\title{
Coffee (Coffea arabica L.) genes early expressed during infection by the rust fungus (Hemileia vastatrix)
}

\author{
DIANA FERNANDEZ ${ }^{1 *}$, PATRICIA SANTOS ${ }^{2}$, CAROLINE AGOSTINI $^{1}$, MARIE-CLAUDE BON ${ }^{1}$, \\ ANNE-SOPHIE PETITOT ${ }^{1}$, MARIA C. SILVA², LEONOR GUERRA-GUIMARÃES², ANA RIBEIRO², \\ XAVIER ARGOUT ${ }^{1}$ AND MICHEL NICOLE' \\ ${ }^{1}$ Institut de Recherche pour le Développement (IRD), UMR 1097 Diversité et Génome des Plantes Cultivées, Equipe Résistance des Plantes, 911 avenue Agropolis, \\ BP64501, 34394 Montpellier Cedex 5, France \\ ${ }^{2}$ Centro de Investigação das Ferrugens do Cafeeiro (CIFC), Quinta do Marquês, 2784-505 Oeiras, Portugal
}

\section{SUMMARY}

The beverage cash crop coffee (Coffea arabica L.) is subject to severe losses caused by the rust fungus Hemileia vastatrix. In naturally resistant coffee plants, a specific hypersensitive reaction (HR) may be elicited early to stop fungal infection. To isolate host genes involved in $\mathrm{HR}$, we undertook an expressed sequence tags (ESTs) analysis. Two cDNA libraries were constructed using suppression subtractive hybridization (SSH) and 527 non-redundant ESTs were generated from 784 randomly picked clones. Classification of the ESTs into several functional categories showed that more than one-quarter of the predicted proteins might encode disease resistance (R) proteins, stress- and defence-proteins, and components of signal transduction pathways. Twenty-eight differentially screened sequences (DSSs) were selected after differential hybridization of 1000 CDNA clones from each library. Investigation of the expression patterns of a subset of 13 DSSs showed higher levels of gene expression in inoculated plants compared with control plants. HR-up-regulation of transcript accumulation occurred for 9 out of the 13 genes 24 and $48 \mathrm{~h}$ after $H$. vastatrix challenge. Two genes encoded homologues of the Arabidopsis DND1 and NDR1 proteins, suggesting conservation of resistance signalling pathways in perennial plants. Other HRregulated sequences matched receptor kinases, AP2 domainand WRKY transcription factors, cytochromes P450, heat shock 70 proteins, glucosyltransferases and proteins of unknown function. The ESTs reported here provide a useful resource for studying coffee resistance responses and for improving $C$. arabica for durable disease resistance.

\footnotetext{
*Correspondence: Fax: +33 4674162 83; E-mail: Diana.Fernandez@mpl.ird.fr †Present adress: European Biological Control Laboratory, Campus International de Baillarguet, 34980 Montferrier le Lez, France.
}

\section{INTRODUCTION}

The coffee plant Coffea arabica L. represents one of the key export and cash crops in tropical and subtropical developing countries. However, this perennial crop is subject to high losses in potential production due to pests and diseases. Coffee leaf rust (CLR) caused by the fungus Hemileia vastatrix (Berkeley \& Broome) is one of the most destructive disease of $C$. arabica, causing premature leaf fall, yield loss and even death of the tree in severe attacks. Natural resistance of $C$. arabica varieties to CLR is conditioned by at least nine major dominant genes $\left(S_{H} 1-S_{H} 9\right)$ (Bettencourt and Rodrigues, 1988; Rodrigues et al., 1975). Nowadays, more than 45 so-called races of the rust pathogen have been determined and effectiveness of some resistant varieties may be reduced by evolution of the parasite virulence (Rodrigues et al., 1975, 1993).

Resistant coffee plants challenged by the rust fungus may undergo a typical hypersensitive reaction (HR) at leaf infection sites (Rodrigues et al., 1975; Silva et al., 2002). The HR may be visualized after 2 days post-inoculation (p.i.) by death of guard and subsidiary cells in stomata where the fungus developed an appressorium and a penetration hypha (Silva et al., 2002). In addition, host cell death may be associated with early accumulation of phenolic-like compounds and encasement of haustorium in plant parietal materials (callose and $\beta$-1,4-glucans). Growth of the fungus in resistant coffee plants usually ceased 4 days p.i., generally before the formation of the first haustorium (Martins and Moraes, 1996; Silva et al., 2002).

Enhancing $C$. arabica resistance to the rust fungus has now become a crucial priority for economic and sustainable coffee production. Among available strategies for improving plant resistance to parasites, those based on induction of host defences (Hammond-Kosack and Parker, 2003; Melchers and Stuiver, 2000) may offer a promising alternative to chemical control and a complement to methods based on introgression of specific resistance genes. Cloning and functional analysis of genes involved in resistance pathways would not only lead to identification of some nonspecific 
genetic components controlling disease resistance to achieve broadspectrum resistance in plants, but would also provide novel tools for germplasm screening. In the last few years, a systematic search of genes involved in the signal transduction pathways leading to the HR and resistance expression has been performed in model plants (Hammond-Kosack and Parker, 2003). Thus far, a broad understanding of the physiological processes that regulate induction of appropriate defences in Arabidopsis, rice or tomato is emerging. In contrast, for perennial crops such as coffee plants, little knowledge is available on the mechanisms by which defence responses are activated and inhibit pathogen growth.

The aim of the present study was to isolate coffee genes involved in the resistance to the rust fungi. We used the suppression subtractive hybridization (SSH) method (Diatchenko et al., 1996) to generate CDNA libraries enriched in sequences expressed in coffee leaves during the early stages of HR. Several studies indicated that a large number of plant genes are transcriptionnally regulated upon challenge by a pathogen (Maleck et al., 2000; Scheideler et al., 2002; Schenk et al., 2000) but that most of them may be common to both compatible and incompatible interactions (Tao et al., 2003). For focusing on genes strictly involved in the $H R$, CDNA from plants infected with an avirulent $H$. vastatrix race (incompatible interaction) were subtracted with CDNA from plants infected with a virulent $H$. vastatrix race (compatible interaction). Here we present the first catalogue of $C$. arabica nonredundant expressed sequence tags (ESTs) and we describe the identification of genes for which expression is regulated during the early events of $H$. vastatrix infection process.

\section{RESULTS}

\section{cDNA library construction and differential screening}

Using the SSH method, two coffee CDNA libraries enriched in sequences specifically expressed during the HR were constructed. The subtraction was conducted by using the incompatible CDNAs sample as the tester, and the compatible cDNAs sample as the driver. Post-inoculation periods of 12,24 and $48 \mathrm{~h}$ were chosen as the appropriate times for isolation of the total RNAs used to construct the subtractive cDNA libraries. Microscopic observations of fungal development indicated that the $H$. vastatrix isolates (i) germinated and developed appressoria (12 h), (ii) penetrated through stomata ( $24 \mathrm{~h}$ ) and (iii) developed haustorial mother cells (HMC) (48 h) (this study and Silva et al., 2002). In the incompatible interaction, the fungus ceased its growth at different stages of the infection process, and death of host cells (guard and subsidiary cells) was initiated around $48 \mathrm{~h}$ (Silva et al., 2002). Library 1 contained subtracted cDNAs obtained from coffee leaves inoculated with the rust fungus for $12 \mathrm{~h}$. Library 2 contained subtracted cDNAs derived from a pool of mRNAs obtained from coffee leaves collected 24 and $48 \mathrm{~h}$ p.i.

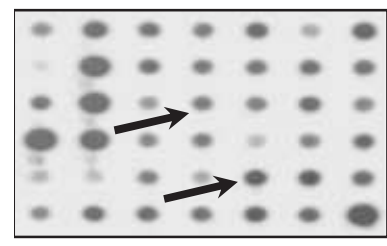

Probe Ru

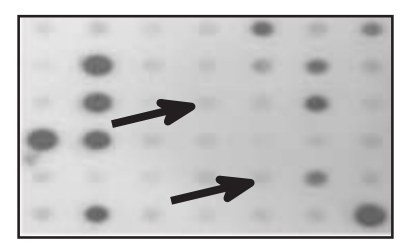

Probe Su
Fig. 1 Example of differential hybridization screening of coffee CDNA clones from the subtractive libraries. Recombinant plasmids (100 ng) carrying CDNA clones were arrayed on Nylon membranes and hybridized with complex cDNA probes obtained from tester (probe Ru) and driver (probe Su) RNA pools. Arrows indicate some examples of clones that were selected based on the intense hybridization signal with probe Ru and the weak signal obtained with probe Su.

In total, more than 2500 recombinant clones were obtained. For each library, 960 clones, selected at random, carried fragments ranging from 190 to $1450 \mathrm{bp}$ (mean $500 \mathrm{bp}$ ). All cDNA clones were screened by differential hybridization against complex CDNA probes generated from tester and driver CDNAs. Probes were carefully equilibrated in terms of specific activity and total radioactivity, ensuring that the same amount of labelled CDNA has been used for each hybridized filter. Thirty-nine CDNA clones (17 and 22 for libraries 1 and 2, respectively) showed a strong hybridization signal with the tester probes and weak or no hybridization with the driver probes (Fig. 1). We partially sequenced all 39 CDNAs (with insert sizes of 400-1450) and conducted a homology search with the BLAST programs. Most (80\%) showed significant homology to plant sequences in databases. After discarding the ribosomal, chloroplastic or mitochondrial DNA sequences, redundant sequences or cDNA fragments matching the same protein from the total set, 28 unique coffee cDNA sequences were identified. Only seven out of the 28 sequences representing $0.7 \%$ of the 960 screened SSH clones originated from library 1. Five clones showed significant similarities with plant proteins in databases (Table 1) and two generated no significant hit when searched using BLAST (data not shown). Among the 21 sequences originating from library 2, representing $2.0 \%$ of the 960 screened SSH clones, 19 clones showed significant similarities with plant proteins in databases (Table 1) and two generated no significant hit when searched using BLAST searches (data not shown).

The 24 differentially screened sequences (DSSs) for which there were significant protein database matches (five and 19 in library 1 and 2, respectively) were classified into one of seven functional categories established so far (Table 1). More than onequarter of the DSSs (seven clones, 29\%) showed moderate to high similarities $\left(10^{-4}<E\right.$-value $\left.<10^{-91}\right)$ with proteins involved in plant cell defence reactions, such as chitinases, cytochrome P450, heat shock proteins (HSP), and components of the Arabidopsis thaliana resistance signalization pathway (non-racespecific disease resistance [NDR1] protein and the ionic channel CNGC2/DND1) involved in the resistance to Pseudomonas syringae 
Table 1 List of 24 differentially screened coffee CDNA sequences and summary of RT-PCR expression analysis.

\begin{tabular}{|c|c|c|c|c|c|}
\hline \multirow[b]{2}{*}{ EST } & \multirow[b]{2}{*}{ BLASTX putative identification* } & \multirow[b]{2}{*}{ E-valuet } & \multirow[b]{2}{*}{ Library } & \multicolumn{2}{|l|}{ Inducibility } \\
\hline & & & & $\begin{array}{l}\text { Incompatible/ } \\
\text { compatible }\end{array}$ & $\begin{array}{l}\text { Incompatible/ } \\
\text { control }\end{array}$ \\
\hline \multicolumn{6}{|c|}{ I. Cell signalling/cell communication } \\
\hline \multicolumn{6}{|c|}{ I.1. channels/transport proteins } \\
\hline DSS1 & >gb|AAF16966.1| ATPase alpha subunit [Pachysandra procumbens] & $8 \mathrm{E}-70$ & 2 & $\mathrm{nt}$ & $\mathrm{nt}$ \\
\hline DSS2 & >ref|NP_042364.1| H+ATPase a subunit [A. thaliana] & $4 \mathrm{E}-13$ & 2 & $\mathrm{nt}$ & $\mathrm{nt}$ \\
\hline DSS3 & >gi|13685|ATPase subunit 9 [A. thaliana] & $1 \mathrm{E}-18$ & 1 & $\mathrm{nt}$ & nt \\
\hline DSS4 & >gi|114527|ATP synthase alpha chain [A. thaliana] & $5 E-71$ & 1 & $\mathrm{nt}$ & $\mathrm{nt}$ \\
\hline DSS5 & $>$ gb|AAB64332.1| Putative membrane transporter [A. thaliana] & $1 \mathrm{E}-26$ & 2 & nt & nt \\
\hline \multicolumn{6}{|c|}{ I.2. Receptors and intracellular transducers } \\
\hline DSS6 & >gi|20521419| Putative receptor-like kinase [0. sativa] & $6 \mathrm{E}-04$ & 2 & + & + \\
\hline DSS7 & >gi|15228670| Putative casein kinase [A. thaliana] & $9 \mathrm{E}-30$ & 1 & $\mathrm{nt}$ & $\mathrm{nt}$ \\
\hline DSS8 & >pir||T07079 Leucine-rich repeat protein LRP [L. esculentum] & $8 \mathrm{E}-29$ & 2 & - & + \\
\hline \multicolumn{6}{|c|}{ II. Cell/organism defence } \\
\hline \multicolumn{6}{|c|}{ II.1. Homeostasis (DNA repair, apoptosis, stress response) } \\
\hline DSS9 & >gi|15222057| Cytochrome P450, putative [A. thaliana] & 1e-35 & 2 & - & + \\
\hline DSS10 & >pir|D71417| Cytochrome P450 [A. thaliana] & $3 \mathrm{E}-20$ & 2 & + & + \\
\hline DSS11 & $>$ gb|AAB97316.1| Heat shock 70 protein [A. thaliana] & $3 \mathrm{E}-61$ & 2 & + & + \\
\hline \multicolumn{6}{|c|}{ II.2. Resistance and defence-related proteins } \\
\hline DSS12 & >ref|NP_188696.1| NDR1 [A. thaliana] & $4 \mathrm{E}-23$ & 2 & + & + \\
\hline DSS13 & >gi 9255920| Cyclic nucl.-gated cation channel DND1 [A. thaliana] & $2 \mathrm{E}-40$ & 2 & + & + \\
\hline DSS14 & >gi|4835584| Acidic chitinase [Glycine max] & $4 \mathrm{E}-12$ & 2 & - & + \\
\hline DSS15 & >gi|2934696| Class III, acidic chitinase [Glycine max] & $6 \mathrm{E}-09$ & 2 & $\mathrm{nt}$ & $\mathrm{nt}$ \\
\hline \multicolumn{6}{|c|}{ III. Gene/protein expression } \\
\hline DSS16 & >gb|AAL11009.1| WRKY31 transcription factor [A. thaliana] & $1 \mathrm{E}-23$ & 2 & + & + \\
\hline DSS17 & >gi|27436378| Dehydration-responsive element binding protein [L. esculentum] & $1 \mathrm{E}-22$ & 1 & + & + \\
\hline DSS18 & >gi|9294635| Oligouridylate binding protein [A. thaliana] & $5 E-44$ & 1 & $\mathrm{nt}$ & $\mathrm{nt}$ \\
\hline \multicolumn{6}{|c|}{ IV. Metabolism } \\
\hline DSS19 & >sp|P06512| Photosystem I P700 chlorophyll A Apoprotein A2 [A. thaliana] & $9 \mathrm{E}-91$ & 2 & $\mathrm{nt}$ & $\mathrm{nt}$ \\
\hline DSS20 & >sp|P06405| Photosystem I P700 chlorophyll A Apoprotein A1 [N. tabacum] & $2 \mathrm{E}-88$ & 2 & $\mathrm{nt}$ & nt \\
\hline DSS21 & >gb|AAF42972.1| Arginine decarboxylase 2 [N. tabacum] & $8 \mathrm{E}-68$ & 2 & $\mathrm{nt}$ & $\mathrm{nt}$ \\
\hline \multicolumn{6}{|c|}{ IV. Unclassified } \\
\hline DSS22 & >gb|AAF61647.1| UDP-glucose: salicylic acid glucosyltransferase [N. tabacum] & $3 \mathrm{E}-15$ & 2 & + & + \\
\hline \multicolumn{6}{|c|}{ VI. Others } \\
\hline DSS23 & >gi|11280502| Hypothetical protein F14F18.180 [A. thaliana] & $1 \mathrm{E}-65$ & 2 & + & + \\
\hline DSS24 & >gb|AAD09508.1|ATFP4 [A. thaliana] & $4 \mathrm{E}-09$ & 2 & - & + \\
\hline
\end{tabular}

*Putative identification indicates the best match to a sequence in the NCBI non-redundant protein database.

tValues greater than e-2 are considered not statistically significant.

‡'-' noninducible, '+' inducible, 'nt' not terted.

(Century et al., 1997; Clough et al., 2000). It is worth noting that none of these DSS originated from library 1, suggesting that only few plant defence responses were activated at $12 \mathrm{~h}$ p.i.

Four DSSs shared sequence similarity with plant proteins that might be involved in defence signal transduction, two with kinase domain-proteins and two with transcription factors. One DSS best matched a glucosyltransferase. Other DSSs matched putatively house-keeping genes $\left(\mathrm{H}^{+}\right.$-ATPases or photosystem proteins) or had homology with putative proteins for which no function had yet been assessed.

\section{Gene expression}

To confirm that DSSs indeed represented differentially expressed genes in the coffee $H R$, their expression patterns were determined during both compatible and incompatible interactions. 


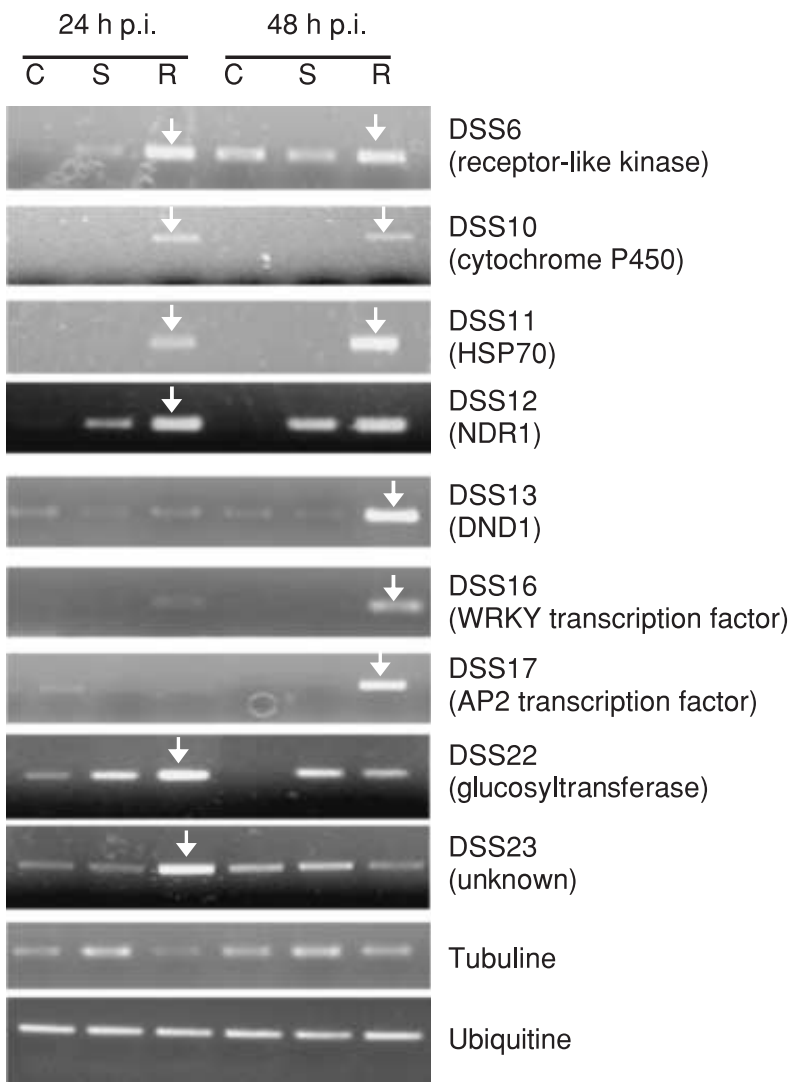

Fig. 2 RT-PCR analysis of transcript levels of coffee genes differentially expressed in $C$. arabica leaves inoculated with $H$. vastatrix (C, non-inoculated plants sprayed with water; $S$, compatible interaction; $R$, incompatible interaction). Clone designation is indicated to the right of each panel. cDNAs were synthesized from RNAs of coffee leaves harvested 24 or $48 \mathrm{~h}$ p.i. using specific primers designed from SSH cDNA sequences. Primers for $C$. arabica alpha-tubuline and ubiquitine genes were used to test for equal cDNA template quantities of samples tested. Arrows indicate differential transcript accumulation in $\mathrm{R}$ as compared with $\mathrm{S}$ samples.

Of the 24 DSSs, we chose to examine only 13 DSSs matching (i) proteins with putative function in resistance signalling or defence reaction, and (ii) proteins with unknown or unclassified function (Table 1). Only one out of the 13 DSSs chosen originated from library 1 (DSS17). Transcript accumulation was first examined by Northern blot hybridization analysis. Because most of the clones corresponded to very low-abundance mRNA (data not shown), transcript levels were also determined more sensitively by semiquantitative RT-PCR. For each candidate gene, expression levels in coffee leaves were monitored during time-course experiments of $12,18,24,36$ and $48 \mathrm{~h}$ after challenge by the rust fungus, in both compatible and incompatible interactions. In addition, gene expression levels were also determined in control leaves only sprayed with water. At least three independent time-course experiments were used on both S4Agaro and Caturra varieties for gene expression studies. The conditions for PCR were optimized to produce unsaturated $\mathrm{PCR}$ product accumulation that retained a linear relationship with the original transcript levels in all samples. Inducibility of the gene expression was investigated by comparing the transcript accumulation in incompatible vs. compatible interactions, or in inoculated plants vs. control plants (Table 1). Inducibility was defined as a clear difference (as visualized by eye) in the transcript accumulation.

For all genes analysed, the transcript accumulation in control plants has been visualized on agarose gels when using a standard number of PCR cycles (26-34, depending on each gene) (data not shown). However, the 13 DSSs clearly showed enhanced transcript accumulation in inoculated plants (compatible or incompatible interaction), over the time-course experiment as compared with control plants (Fig. 2). In addition, nine out of the 13 genes also showed transient enhanced transcript accumulation during the incompatible interaction when comparing with the compatible interaction. DSS17, the only clone tested from library 1 , and eight out of the 12 tested clones from library 2 showed higher levels of transcript accumulation around 24 and $48 \mathrm{~h}$ p.i. (Fig. 2). As expected, DSS17 also displayed over-expression $12 \mathrm{~h}$ p.i., but to a lower extent than at later times (data not shown). Therefore, the gene expression analyses confirmed the differential hybridization screening process for most of the DSSs tested (one of one for library 1, and eight of 12-67\%-for library 2).

The HR-up-regulated sequences putatively encoded receptor kinase (DSS6), cytochrome P450 (DSS10), HSP70 (DSS11), homologues of the $A$. thaliana NDR1 and DND1 proteins (DSS12 and 13 , respectively), transcription factors (DSS16 and 17) and a UDP-glucose: salicylic acid glucosyltransferase (DSS22). DSS23 matched a protein of unknown function.

\section{ESTs}

In order to obtain a catalogue of expressed genes in rust-infected coffee plants, we also generated ESTs from clones that were not selected in the differential screening process. A total of 768 clones (384 for each library) were randomly chosen and partially sequenced. After editing, 527 non-redundant sequences were used in database searches. Of these, 433 (82\%) ESTs showed similarities $\left(E\right.$-value $\leq \mathrm{e}^{-3}$ ) to plant protein database entries, while no significant matches were found in the protein databases for the remaining clones. ESTs matching the same plant protein but with different nucleotide sequences, were considered as CDNA fragments derived from a single coffee transcript. Only the best matching EST sequence was included in this study. At the end, only 402 (76\%) ESTs matching unique plant proteins were considered for further analysis of libraries.

Sequences that did not show significant matches to the protein databases were also scrutinized against nucleotide databases at NCBI using the BLASTN algorithm. Fourteen out of 45 sequences from library 1 and 13 out of 51 sequences from library 


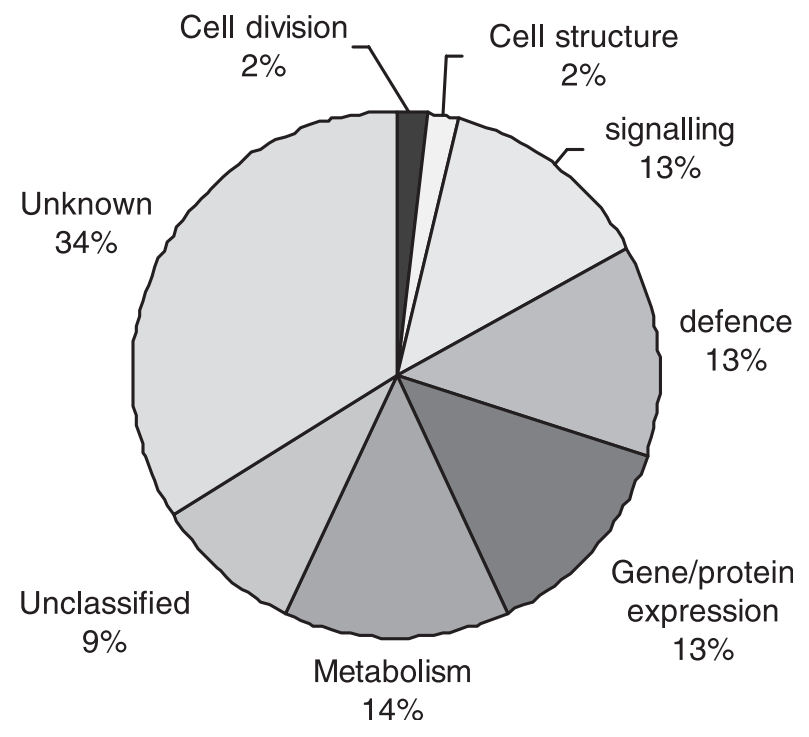

Fig. 3 EST classification according to putative biological function following the Expressed gene Anatomy database cellular role classification scheme (White and Kerlavage, 1996), based on homologies to sequences of known function detected by BLASTX searches.

2 were identified as having moderate to high similarity to plant ESTs or chloroplastic DNA sequences (data not shown).

The sequenced CDNAs for which there were significant protein database matches were classified into one of seven functional categories (see Supplementary material: Tables S1 and S2). No significant quantitative differences were observed between libraries prepared at different times after inoculation. Figure 3 presents the distribution of the 402 ESTs into functional categories. The highest proportion of cDNAs (34\%) were homologous to plant genes of unknown function. Other ESTs encompassed components of cell signalling/communication (13\%), cell/organism defence $(13 \%)$, gene/protein expression (13\%) and metabolism (14\%). Genes associated with cell division or structure/motility were poorly represented in these libraries.

Table 2 presents ESTs of the cell/organism defence functional category, which is subdivided into components of cell homeostasis maintenance and resistance and defence-related proteins. Genes functionally associated to the former category included proteins known to be involved in apoptosis regulation in animal cells (Beclin and macrophage migration inhibitory factor), in several oxidative pathways (cytochrome P450 and oxidoreductases), in metal homeostasis and detoxification (metallothioneins) and, finally, in response to several stresses (HSPs). The CDNA clones associated with the resistance and defence-related proteins category included putative homologues of resistance proteins and components of the resistance signalling pathway (Arabidopsis non-race-specific disease resistance [NDR1] protein). Two ESTs with homology to proteins involved in specific resistance to pathogens (tomato Asc-1 protein, pepper importin alpha2) were found, as well as four ESTs displaying homology to disease resistance (R) proteins of the CC-NBS-LRR class (CA-H11-01_B09, CAH11-02_D06 and CA-H11-03_E03) or the tomato Cf-family (CA-H11-04_G04). Other clones of libraries 1 and 2 assigned to this category matched proteins involved in defence reactions, such as the pathogenesis-related (PR) proteins (chitinases, $\beta 1,3$-glucanases, PR-10), the chalcone synthase and the lipoxygenase enzymes.

\section{DISCUSSION}

In this study, we successfully isolated genes that might be associated with expression of early resistance mechanisms of coffee plants to $H$. vastatrix. Of the 402 annotated ESTs, at least $13 \%$ may represent genes involved in plant defence reactions and $13 \%$ in signalling processes (Fig. 3). To our knowledge, these CDNA sequences are the first ESTs in the important cash-crop genera Coffea reported so far. Only a few genes, which are involved in the biosynthesis of caffeine or in seed development, have already been cloned in C. arabica (Marraccini et al., 1999; Uefuji et al., 2003). The ESTs we isolated here may therefore provide new insights into the biology of this perennial woody plant species. Database searches showed that the predicted proteins encoded by the coffee ESTs had homologies with disease resistance proteins, stress- and defence-proteins, and components of cell signalling pathways (Tables 1 and 2). As an example, ESTs with similarity to known R proteins of the NBS-LRR and Cffamilies were found, suggesting that several classes of $R$ genes (Hammond-Kosack and Jones, 1997) are also present in the Coffea genome. Until now, only NBS-like type DNA sequences have been described in C. arabica and C. canephora (Noir et al., 2001) and no data about their putative transcription in planta are available. Expression analysis of the $\mathrm{R}$ genes-related ESTs isolated here showed they were constitutively transcribed in coffee leaves (data not shown). In the same way, ESTs encoding several families of PR-proteins were found in both libraries (Table 2), but none was recovered among the DSSs, indicating that at this early stage of the HR no specific activation of PR genes might have occurred.

Use of the SSH technology followed by differential hybridization screening resulted in the identification of 28 DSSs [seven $(0.7 \%)$ and $21(2 \%)$ for library 1 and 2, respectively] that are preferentially expressed during the incompatible interaction. RTPCR analyses of a subset of 13 DSSs showed that they were all induced during the $\mathrm{C}$. arabicalH. vastatrix interaction, and that most of them (nine out of 13) were indeed transcriptionally regulated during HR. The enhanced accumulation of transcripts around $24 \mathrm{~h}$ p.i. that we observed for several genes suggest, together with the cytological data (Silva et al., 1999, 2002), that induction of resistance responses of coffee cell leaves might occur soon after the penetration of the hyphae into the substomatal chamber. 
Table 2 Summary of ESTs assigned to the cell/organism defence category.

\begin{tabular}{|c|c|c|c|}
\hline ESTS & BLASTX putative identification* & E-valuet & Library \\
\hline \multicolumn{4}{|c|}{ Homeostasis (DNA repair, apoptosis, stress response) } \\
\hline CA-H11_01_B05 & >sp|Q9M367| Beclin 1-like protein [A. thaliana] & $1 \mathrm{E}-13$ & 2 \\
\hline CA-H11_02_B06 & >pir|T14337| DNA repair protein RAD23 protein [Daucus carota] & $1 \mathrm{E}-21$ & 2 \\
\hline CA-H12_04_A09 & >gi|15241023| Macrophage migration inhibitory factor [A. thaliana] & $2 \mathrm{E}-26$ & 1 \\
\hline CA-H11_01_B01 & >gb|AAG28426.1| Cytosolic aconitase [N. tabacum] & $2 \mathrm{E}-57$ & 2 \\
\hline CA-H11_04_E06 & >pir|T10464| Fatty acid oxidation tetrafunctional protein [Cucumis sativus] & $4 \mathrm{E}-70$ & 2 \\
\hline CA-H12_03_CO3 & >sp|P06409| NADH-plastoquinone oxidoreductase subunit K [N. tabacum] & $6 \mathrm{E}-17$ & 1 \\
\hline CA-H12_04_G04 & $>\operatorname{tr|}$ Q9M3T6| Glutathione reductase (Fragment) [Betula verrucosa] & $2 \mathrm{E}-88$ & 1 \\
\hline CA-H12_03_C11 & $>\operatorname{tr|}$ Q9LRC4| Oxygen evolving enhancer protein 1 precursor [Bruguiera gymnorrhiza] & $1 \mathrm{E}-92$ & 1 \\
\hline CA-H11_02_B09 & >sp|P93530| Cytochrome P450 [Solanum chacoense] & $1 \mathrm{E}-23$ & 2 \\
\hline CA-H11_02_E04 & >emb|CAA70575.1| Cytochrome P450 [Nepeta racemosa] & $7 \mathrm{E}-51$ & 2 \\
\hline CA-H11_03_B07 & >dbj|BAB56089.1| Cytochrome P450-like protein [0. sativa] & $3 \mathrm{E}-32$ & 2 \\
\hline CA-H11_04_H05 & >ref|NP_172734.1| Cytochrome P450 putative [A. thaliana] & $2 \mathrm{E}-11$ & 2 \\
\hline CA-H12_04_E07 & >sp|P93531| Cytochrome P450 [Solanum chacoense] & $2 \mathrm{E}-24$ & 1 \\
\hline CA-H11_02_B08 & >gb|AAK77908.1|AAA-metalloprotease FtsH [Pisum sativum] & $3 \mathrm{E}-44$ & 2 \\
\hline CA-H11_03_D08 & >gi|508296| Metallothionein I [ Coffea arabica] & $6 \mathrm{E}-16$ & 2 \\
\hline CA-H12_02_E08 & >sp|P20238| Metallothionein-like protein 1 [Mimulus guttatus] & $5 \mathrm{E}-16$ & 1 \\
\hline CA-H12_01_D02 & >sp|P43396| Metallothionein-like protein 1 [Coffea arabica] & $3 \mathrm{E}-08$ & 1 \\
\hline CA-H11_01_B06 & >pir|S53126| dnaK-type molecular chaperone hsp70 [0. sativa] & $9 \mathrm{E}-64$ & 2 \\
\hline CA-H11_02_F10 & >sp|P35016| Heat shock protein 90 [Catharanthus roseus] & $2 \mathrm{E}-42$ & 2 \\
\hline CA-H11_02_G08 & >gb|AAF34134.1| High molecular weight heat shock protein [Malus domestica] & $1 \mathrm{E}-14$ & 2 \\
\hline CA-H11_04_A11 & >gb|AAF31705.1| Heat-shock protein 80 [Euphorbia esula] & $4 \mathrm{E}-36$ & 2 \\
\hline CA-H11_01_CO2 & >gi|5734767| Stress-related SRG1 protein [A. thaliana] & $7 \mathrm{E}-24$ & 2 \\
\hline CA-H12_03_B10 & >sp|Q9SW70| Stress-related protein [Vitis riparia] & $1 \mathrm{E}-26$ & 1 \\
\hline CA-H11_02_A05 & $>$ dbj|BAB64185.1| Putative pir7b (Pseudomonas inducible protein) [0. sativa] & $2 \mathrm{E}-25$ & 2 \\
\hline CA-H11_03_G11 & >pir|T14329| Dermal glycoprotein precursor. extracellular [Daucus carota] & $7 \mathrm{E}-12$ & 2 \\
\hline CA-H12_03_D08 & >tr|Q9SP21| Dehydrin like protein, Bdn1 (Fragment) [Boea crassifolia] & $5 \mathrm{E}-20$ & 1 \\
\hline \multicolumn{4}{|c|}{ Resistance and defence-related proteins } \\
\hline CA-H11_01_B09 & >gb|AAC02202.1| Resistance protein candidate [Lactuca sativa] & $9 \mathrm{E}-06$ & 2 \\
\hline CA-H11_02_B04 & $>$ gi|16974114| Putative resistance protein (asc-1 gene) [L. esculentum] & $8 \mathrm{E}-17$ & 2 \\
\hline CA-H11_02_D06 & >gb|AAF44097.1| Disease resistance-like protein [Glycine max] & $1 \mathrm{E}-12$ & 2 \\
\hline CA-H11_03_E03 & >emb|CAB50786.1| Rx protein [Solanum tuberosum] & 0002 & 2 \\
\hline CA-H11_04_G04 & >gi|14330714| HcrVf1 protein [Malus floribunda] & $5 \mathrm{E}-15$ & 2 \\
\hline CA-H11_04_A05 & >gb|AAK38727.1| Importin alpha 2 [Capsicum annuum] & $2 \mathrm{E}-67$ & 2 \\
\hline CA-H11_03_H01 & $>$ ref|NP_188696.1| Non-race specific disease resistance protein (NDR1) [A. thaliana] & $4 \mathrm{E}-23$ & 2 \\
\hline CA-H11_03_A12 & >sp|P29024| Acidic endochitinase precursor [ Vigna angularis] & $1 \mathrm{E}-28$ & 2 \\
\hline CA-H11_03_D05 & >gb|AAD22114.1| Chitinase [Fragaria $x$ ananassa] & $2 \mathrm{E}-24$ & 2 \\
\hline CA-H11_04_E02 & >pir||T05187| Class III acidic chitinase [Glycine max] & $8 \mathrm{E}-24$ & 2 \\
\hline $\mathrm{CA}-\mathrm{H} 12$ _02_G12 & $>\operatorname{tr}|048642|$ Class III acidic endochitinase precursor [ Glycine max] & $2 \mathrm{E}-09$ & 1 \\
\hline CA-H12_01_A04 & >tr|AAL01886| Chitinase 3-like protein [Trichosanthes kirilowil] & $2 \mathrm{E}-41$ & 1 \\
\hline CA-H12_02_B01 & $>\operatorname{tr} \mid$ Q9M2U5| Class IV chitinase $[A$. thaliana] & $4 \mathrm{E}-83$ & 1 \\
\hline CA-H12_03_A05 & $>\operatorname{tr} \mid$ Q9SHZ2| Putative beta-1,3-glucanase [A. thaliana] & $2 \mathrm{E}-47$ & 1 \\
\hline CA-H11_01_G04 & >ref|NP_176656.1| Beta-1.3-glucanase. putative [A. thaliana] & $9 \mathrm{E}-37$ & 2 \\
\hline CA-H11_04_F12 & >emb|CAC16166.1| Pathogenesis-related protein 10 [Vitis vinifera] & $6 \mathrm{E}-18$ & 2 \\
\hline CA-H11_04_B08 & >gb|AAL16409.1| Pathogenesis-related protein PR10a [Nicotiania tabacum] & $8 \mathrm{E}-14$ & 2 \\
\hline CA-H12_03_B12 & >sp|Q9ZRS4| Chalcone synthase [Catharanthus roseus] & e-101 & 1 \\
\hline CA-H12_04_G05 & >tr|BAA87338| Chalcone synthase [Pharbitis nil] & $5 \mathrm{E}-37$ & 1 \\
\hline CA-H12_03_F03 & $>\operatorname{tr} \mid$ Q9FNX7| Lipoxygenase (Fragment) [A. thaliana] & $4 \mathrm{E}-64$ & 1 \\
\hline CA-H11_01_G11 & >gi|2655291| Probable germin (oxalate oxidase) protein 4 [O. sativa] & $6 \mathrm{E}-29$ & 2 \\
\hline CA-H11_02_H11 & >ref|NP_174357.1| Putative reticuline oxidase-like protein [A. thaliana] & $3 \mathrm{E}-55$ & 2 \\
\hline CA-H11_01_B08 & >tr|Q944N4| TMV Helicase domain-binding protein [Nicotiania tabacum] & $3 \mathrm{E}-46$ & 2 \\
\hline CA-H11_02_E07 & >gp|AY062850| Hypersensitive-induced response protein [A. thaliana] & $2 \mathrm{E}-35$ & 2 \\
\hline CA-H12_02_A12 & $>\operatorname{tr} \mid$ P93378| Tumour-related protein [N. tabacum] & $1 \mathrm{E}-30$ & 1 \\
\hline CA-H12_03_B11 & >sp|P05993| Cysteine proteinase [Carica papaya] & $2 \mathrm{E}-10$ & 1 \\
\hline
\end{tabular}

*Putative identification indicates the best match to a sequence in the NCBI non-redundant protein database.

tValues greater than $\mathrm{e}-2$ are considered not statistically significant. 
Based on sequence similarity to known genes, four out of the nine HR-up-regulated sequences putatively encoded stressrelated proteins or components of disease resistance signalling pathways (Table 1). Two HR-up-regulated sequences matched cytochromes P450 and HSP70. Some reports of up-regulation of these genes during several plant-pathogen interactions exist in the literature (Birch et al., 1999; Cheong et al., 2002; Takemoto et al., 1999; Xiong et al., 2001), suggesting that these proteins may play a role in plant defence mechanisms. Cytochrome P450 genes may be involved in the biosynthesis of defence-related compounds, such as the Arabidopsis PAD3 gene required for camalexin synthesis in the resistance response to Alternaria brassicicola (Zhou et al., 1999). Recently, Kanzaki et al. (2003) showed that members of the HSP70 and 90 families were essential components of the plant defence signal transduction pathway. Concerning other HR-up-regulated sequences encoding resistance-signalling components, two coffee sequences best matched the $A$. thaliana DND1 and NDR1 proteins. The DND1 (defence, no death) protein is a cyclic nucleotide-gated ion channel (AtCNGC2) involved in the HR signalling pathway to $P$. syringae (Clough et al., 2000). The AtCNGC2 gene has been shown to be transiently induced during leaf and cell culture senescence, suggesting a potential function in the initiation of developmentally regulated cell death programs (Kohler et al., 2001). The NDR1 (non-race-specific disease resistance) protein is a key component of the signalling pathway of many CC-NBS-LRR resistance proteins (Century et al., 1997). In the P. syringae-A. thaliana interaction, NDR1 expression is induced in response to pathogen challenge (Century et al., 1997). Isolation of ESTs displaying similar expression patterns and sequence homology to DND1 and NDR1 suggest they might have a potential role in the resistance of $C$. arabica to $H$. vastatrix. In addition, ESTs matching $\mathrm{R}$ proteins of the CC-NBS-LRR class were also identified in library 2 (Table 2). All together, these data indicate the conservation of some components of R-gene-mediated resistance signalling pathways in coffee plants.

Finally, in addition to the HR-up-regulated CDNA clones that were directly associated with the cell/organism defence functional category, we identified four other entities (DSS6, 16, 17 and 22) of potential interest regarding defence mechanisms (Table 1). DSS6 putatively encoded a receptor-like kinase. This class of signalling proteins is involved in a diverse array of developmental and defence functions (Du and Chen, 2000; Morris and Walker, 2003). DSS22 best matched a UDP-glucose: salicylic acid glucosyltransferase. Glucosyltransferases catalyse the transfer of glucose residues to numerous substrates and regulate the activity of compounds that play important roles in plant defence against pathogens, such as salicylic acid (Chong et al., 2002).

DSS16 and 17 putatively encoded an AP2-type transcription factor and a WRKY transcription factor, respectively. A number of gain-of-function studies have shown the direct implication of several transcription factors in potentiating the plant responses to pathogen infection (He et al., 2001; Park et al., 2001; Robatzek and Somssich, 2001; Shin et al., 2002; Vailleau et al., 2002). Particularly involved are several WRKY proteins, the genes of which may be rapidly induced by pathogens or treatment with SA (Asai et al., 2002; Chen and Chen, 2002; Du and Chen, 2000; Eulgem et al., 1999; Robatzek and Somssich, 2001). The promoter element (W-box) that binds WRKY proteins has been found in several A. thaliana genes, which exhibited common regulation patterns under different systemic acquired resistance (SAR)-inducing or -repressing conditions (Maleck et al., 2000). Because transcription factors may be crucial components of early resistance signalling through regulation of expression of genes involved in defence reactions, the two coffee sequences matching these regulatory proteins may play an important role in the mechanisms of coffee plant resistance to parasites.

In conclusion, this investigation has provided insights into the nature of pathogen-responsive genes in coffee leaves. This is the first study aimed at specifically targeting transcripts participating in resistance cell signalling elicited in response to the rust fungus. Although far from being exhaustive, the ESTs reported here may provide useful data for improving our knowledge of coffee resistance to parasites. In addition, these genes may allow comparative analysis of the resistance mechanisms in perennial plants with those reported in model plants. The ESTs may also be used as candidate genes for developping molecular markers to assist coffee genetics programmes. Defence-related genes have proven useful in cereals and cacao programmes aimed at improving plants for increased disease resistance (Borrone et al., 2004; Ramalingam et al., 2003). Future work will aim to understand the role of the HR-up-regulated clones in the mechanisms of C. arabica resistance to the rust fungus. The recent success in producing transgenic decaffeinated coffee plants using mechanisms of RNA interference (Ogita et al., 2003) paved the way for the functional characterization of coffee CDNA clones by Agrobacteriummediated plant silencing assays.

\section{EXPERIMENTAL PROCEDURES}

\section{Plant variety, fungal strains, and inoculation}

Coffea arabica var. S4 Agaro (used to construct SSH libraries and for gene expression studies) and C. arabica var. Caturra (used to confirm gene expression studies) were kept in the greenhouse. Sets of equally aged plants were transferred to a growth chamber (Cryo-Rivoire, Saint-Gély du Fesc, France) under 100\% relative humidity, at $25^{\circ} \mathrm{C}$ and under $12 \mathrm{~h}$ light before being inoculated with $H$. vastatrix. Plants were inoculated with $H$. vastatrix isolates, either eliciting an incompatible interaction (race VI with Caturra; race II with S4 Agaro) or a compatible interaction (race II with Caturra; race XIV with S4 Agaro) as described in Silva et al. (2002). Leaves were collected at various times after inoculation, 
quickly dissected to remove the central vein, then immediately frozen in liquid nitrogen and stored at $-80^{\circ} \mathrm{C}$ until RNA extraction. At each collection time and for each $\mathrm{H}$. vastatrix strain, germination of spores and infection stage were controlled by collecting small leaf pieces, staining them with fluorescent brightener (Sigma F-6259) for 5 min and microscopically examining them under UV light.

\section{RNA extraction}

For each sample, four leaves collected from two coffee plants were mixed and total RNAs were extracted using the RNeasy Plant kit (Qiagen, France) completed by a DNAse treatment. Quality and concentration of RNA were checked on denaturing agarose gel and by absorbance measurements at 230, 260 and $280 \mathrm{~nm}$ on a UV spectrophotometer.

\section{Construction of the coffee subtractive cDNA libraries}

For SSH library $1,1 \mu \mathrm{g}$ total RNA of incompatible and compatible samples was obtained from coffee leaves collected $12 \mathrm{~h}$ p.i. For SSH library 2, $1 \mu \mathrm{g}$ total RNA of incompatible and compatible samples was obtained by pooling $500 \mathrm{ng}$ each of total RNA from coffee leaves collected at $24 \mathrm{~h}$ and $48 \mathrm{~h}$ p.i.

Total RNAs were used to produce SMART-CDNAs using the SMART-PCR CDNA synthesis kit (Clontech, Palo Alto, CA). The subtractive CDNA libraries were obtained using the PCRSelect CDNA Subtraction kit (Clontech). The tester (incompatible) SMART-CDNA sample was subtracted twice by the driver (compatible) SMART-cDNA sample following the manufacturer's recommendations (forward subtraction). We also performed a reverse subtraction, in which the tester served as the driver and the driver as the tester, in order to produce complex cDNA probes for further differential screening of the subtracted clones.

All PCR amplifications were carried out using the Advantage CDNA PCR kit (Clontech). The cDNA purification steps were performed using the High Pure PCR Product Purification kit (Roche, Meylan, France). To enhance cloning efficiency, the secondary PCR products (forward subtraction) were purified, and subjected to $3^{\prime}$ adenine addition by incubating them for $30 \mathrm{~min}$ at $72{ }^{\circ} \mathrm{C}$ with $200 \mu \mathrm{M}$ dATP and non-proofreading Taq polymerase (Goldstar, Eurogentec, Seraing, Belgium). Subtracted cDNA sequences were then immediately ligated into a plasmid vector (pGEM-T easy kit, Promega, France, for SSH library 1 and pCR2.1-TOPO cloning kit, InVitrogen, France, for SSH library 2) and used to transform Escherischia coli competent cells.

\section{Differential screening of subtracted cDNA clones}

Selection of CDNA clones specifically expressed in the resistant samples was performed by differential screening of the subtrac- tive libraries. Overall recommendations of the PCR-Select Differential Screening kit User Manual (Clontech) were followed, except for the preparation of probes, which were digested with Rsal, Eael and Smal to remove adaptaters as described in Tkatchenko et al. (2000). After purification, recombinant bacterial colonies were arrayed on Nylon membranes (Hybond NX, Amersham, France). Four sets of membranes were prepared and hybridized with the radiolabelled tester (Ru), driver (Su), forward-subtracted tester (R) and reverse-subtracted driver (S) probes, respectively. Specific activity of each probe was determined using a scintillation counter, and $80-100 \times 10^{6}$ c.p.m. of probe was used per filter. Only clones showing an intense hybridization signal with probes $\mathrm{Ru}$ and $\mathrm{R}$ and a weak signal with probes Su and S were selected. Results of the first screening were confirmed by another of differential hybridization on purified plasmids extracted from selected clones (50 and $100 \mathrm{ng}$ ) arrayed on Nylon membranes (Hybond $\mathrm{N}+$, Amersham).

\section{Sequencing and bioinformatic analysis of cDNA clones}

Plasmids DNA from cDNA clones was extracted and partially sequenced by single-pass runs (Sequençing centres of INRA, Nancy, and Génopole, Montpellier, France). We have developed an automated, iterative system for comprehensive DNA sequence analysis and gene annotation for comparative genomics. The 'annotation pipeline' consists of Perl modules developed for sequence trimming, analysis, annotation and visualization. Its main features include clustering of nucleotide sequences and comparative homology searching. The pipeline uses a number of publicly available analysis programs to annotate a DNA sequence. Homology to sequences present in international databases was searched using Basic local alignment search tools (BLASTN and BLASTX) (Altschul et al., 1990) developed the National Center for Biotechnology Information (NCBI) website (http://www.ncbi.org). The sequenced CDNAs with significant database matches ( $E$-value $<10^{-3}$ ) were classified into one of seven functional categories following the Expressed gene Anatomy database cellular role classification scheme (White and Kerlavage, 1996) using The Institute for Genomic research (TIGR) website (http://www.tigr.org).

The sequence data described in this paper have been submitted to GenBank under accession numbers CF588584 to CF589197.

\section{RT-PCR}

Specific gene primers were designed from DNA sequence of each gene to be analysed using the Primer3 software (Rozen and Skaletsky, 2000). A control PCR was run on extracted RNA samples to check the absence of genomic DNA. First-strand CDNAs were synthesized from $2 \mu \mathrm{g}$ of total RNA in $20 \mu \mathrm{L}$ final volume, using Omniscript RT kit (Qiagen) and oligo-dT(18) primer (Eurogentec, Seraing, 
Belgium) following the manufacturer's instructions. Depending on the gene, $0.1-0.4 \mu \mathrm{L}$ RT reaction (10-40 ng starting RNA) was used in PCR reactions with specific gene primers.

To quantify template quantities, the RT-PCR reaction was stopped as soon as possible in order to maintain initial differences in target transcript quantities (exponential phase of amplification). For each gene, optimal PCR cycle number was chosen empirically so that the PCR products could hardly be detected by ethidium bromide staining in agarose gels. Depending on the genes, PCR reactions were subjected to $17-35$ cycles at $95{ }^{\circ} \mathrm{C}$ (30 s), $52-58^{\circ} \mathrm{C}(30 \mathrm{~s})$ and $72{ }^{\circ} \mathrm{C}(30 \mathrm{~s})$ with Hot Goldstar DNA polymerase (Eurogentec, Belgium). Ten microlitres from each PCR reaction was fractionated on a $1.5 \%(\mathrm{w} / \mathrm{v})$ agarose gel in Tris-acetate EDTA buffer and stained with $0.5 \%(\mathrm{w} / \mathrm{v})$ ethidium bromide. The gels were photographed with a Digital Imaging System (GelDoc 2000, Bio-Rad, Paris, France). The intensity of the ethidium-bromide-stained DNA bands was estimated by eye.

Alpha-tubulin and ubiquitin cDNAs, used as internal constitutive control, were amplified using coffee-specific primers (tubuline: 5'-GAGAGAGTGCATCTCCATCCAT- $3^{\prime}$ and 5'-CTGCTCAGGGTGGAAGAGTT-3'; ubiquitin: 5'-GGGTGGAGGAGAAAGAAGGAAT$3^{\prime}$ and $5^{\prime}$-CTCCACCTCTCAGAGCAAGAAC-3') designed from the cloned sequences (tubuline: GenBank accession AF363630, A.L. Gaitan and H.S. Aldwinckle, unpublished data; ubiquitin: GenBank accession AF297089, R. Rojas-Herrera et al., unpublished data).

For the analysis of gene expression, two sets of RT-PCR were conducted with two independently isolated total RNA samples from at least three independent plant inoculation experiments on both S4Agaro and Caturra varieties.

\section{SUPPLEMENTARY MATERIAL}

The authors have provided the following supplementary material, which can be accessed from http://www.blackwellpublishing. com/products/journals/suppmat/MPP/MPP250/MPP250sm.htm: Table S1 ESTs isolated from $H$. vastatrix-infected coffee SSH library 1.

Table S2 ESTs isolated from $H$. vastatrix-infected coffee SSH library 2.

\section{ACKNOWLEDGEMENTS}

We wish to thank J. Aribi (IRD) for culture and maintenance of the coffee plants, F. Andrieu, J-M. Assié and P. Galaup for their technical assistance. This work was partly supported by a joint cooperation programme of the French Embassy and the International Institute of Scientific and Technologic Cooperation (Portugal). P.S. was supported by a fellowship from the Scientific and Technologic Fundation of Portugal. Sequencing of the CDNA clones was supported by the Groupement d'Intérêt Scientifique Montpellier Languedoc-Roussillon Génopole, France.

\section{REFERENCES}

Altschul, S.F., Gish, W., Miller, W., Myers, E.W. and Lipman, D. (1990) Basic local alignment search tool. J. Mol. Biol. 215, 403-410.

Asai, T., Tena, G., Plotnikova, J., Willmann, M.R., Chiu, W.L., GomezGomez, L., Boller, T., Ausubel, F.M. and Sheen, J. (2002) MAP kinase signalling cascade in Arabidopsis innate immunity. Nature, 415, 977-983.

Bettencourt, A.J. and Rodrigues, C.J. Jr (1988) Principles and practice of coffee breeding for resistance to rust and other disease. In Coffee, Vol. 4 Agronomy (Clarke, R.J. and Macrae, R., eds). London: Elsevier Applied Science, pp. 199-234.

Birch, P.R.J., Avrova, A.O., Duncan, J.M., Lyon, G.D. and Toth, R.L. (1999) Isolation of potato genes that are induced during an early stage of the hypersensitive response to Phytophthorai Infestans. Mol. Plant-Microbe Interact. 12, 356-361.

Borrone, J.W., Kuhn, D.N. and Schnell, R.J. (2004) Isolation, characterization, and development of WRKY genes as useful genetic markers in Theobroma cacao. Theor. Appl. Genet. 109, 495-507.

Century, K.S., Shapiro, A.D., Repetti, P.P., Dahlbeck, D., Holub, E. and Staskawicz, B.J. (1997) NDR1, a pathogen-induced component required for Arabidopsis disease resistance. Science, 278, 1963-1965.

Chen, C. and Chen, Z. (2002) Potentiation of developmentally regulated plant defense response by AtWRKY18, a pathogen-induced Arabidopsis transcription factor. Plant Physiol. 129, 706-716.

Cheong, Y.H., Chang, H.-S., Gupta, R., Wang, X., Zhu, T. and Luan, S. (2002) Transcriptional profiling reveals novel interactions between wounding, pathogen, abiotic stress, and hormonal responses in Arabidopsis. Plant Physiol. 129, 661-677.

Chong, J., Baltz, R., Schmitt, C., Beffa, R., Fritig, B. and Saindrenan, P. (2002) Downregulation of a pathogen-responsive tobacco UDP-Glc: phenylpropanoid glucosyltransferase reduces scopoletin glucoside accumulation, enhances oxidative stress, and weakens virus resistance. Plant Cell, 14, 1093-1107.

Clough, S.J., Fengler, K.A., Yu, I.C., Lippok, B., Smith, R.K. and Bent, A.F. (2000) The Arabidopsis dnd1 'defense, no death' gene encodes a mutated cyclic nucleotide-gated ion channel. Proc. Natl Acad. Sci. USA, 97, 9323-9328.

Diatchenko, L., Lau, Y.F.C., Campbell, A.P., Chenchik, A., Moqadam, F., Huang, B., Lukyanov, S., Lukyanov, K., Gurskaya, N., Sverdlov, E.D. and Siebert, D. (1996) Suppression subtractive hybridization, a method for generating differentially regulated or tissue-specific CDNA probes and libraries. Proc. Natl Acad. Sci. USA, 93, 6025-6030.

Du, L. and Chen, Z. (2000) Identification of genes encoding receptor-like protein kinases as possible targets of pathogen- and salicylic acidinduced WRKY DNA-binding proteins in Arabidopsis. Plant J. 24, 837-847.

Eulgem, T., Rushton, P.J., Schmelzer, E., Hahlbrock, K. and Somssich, I.E. (1999) Early nuclear events in plant defence signalling, rapid gene activation by WRKY transcription factors. EMBO J. 18, 4689-4699.

Hammond-Kosack, K.E. and Jones, J.D.G. (1997) Plant disease resistance genes. Annu. Rev. Plant Physiol. Mol. Biol. 48, 575-607.

Hammond-Kosack, K.E. and Parker, J.E. (2003) Deciphering plantpathogen communication: fresh perspectives for molecular resistance breeding. Curr. Opin. Biotechnol. 14, 177-193.

He, P., Warren, R.F., Zhao, T., Shan, L., Zhu, L., Tang, X. and Zhou, J.M. (2001) Overexpression of Pti5 in tomato potentiates pathogeninduced defense gene expression and enhances disease resistance to 
Pseudomonas syringae pv. tomato. Mol. Plant-Microbe Interact. 14, 1453-1457.

Kanzaki, H., Saitoh, H., Ito, A., Fujisawa, S., Kamoun, S., Katou, S., Yoshioka, H. and Terauchi, R. (2003) Cytosolic HSP90 and HSP70 are essential components of INF1-mediated hypersensitive response and non-host resistance to Pseudomonas cichorii in Nicotiana benthamiana. Mol. Plant Pathol. 4, 383-391.

Kohler, C., Merkle, T., Roby, D. and Neuhaus, G. (2001) Developmentally regulated expression of a cyclic nucleotide-gated ion channel from Arabidopsis indicates its involvement in programmed cell death. Planta, 213, 327-332.

Maleck, K., Levine, A., Eulgem, T., Morgan, A., Schmid, J., Lawton, K.A., Dangl, J.L. and Dietrich, R.A. (2000) The transcriptome of $A$. thaliana during systemic acquired resistance. Nat. Genet. 26, 403-410.

Marraccini, P., Deshayes, A., Petiard, V. and Rogers, W.J. (1999) Molecular cloning of the complete 11s seed storage protein gene of Coffea arabica and promoter analysis in transgenic tobacco plants. Plant Physiol. Biochem. 37, 273-282.

Martins, E.M.F. and Moraes, W.B.C. (1996) Development of Hemileia vastatrix in coffee plants with genetic or induced vesistance. J. Phytopathol. 144, 519-526.

Melchers, L.S. and Stuiver, M.H. (2000) Novel genes for disease-resistance breeding. Curr. Opin. Plant Biol. 3, 147-152.

Morris, E. and Walker, J. (2003) Receptor-like protein kinases, the keys to response. Curr. Opin. Plant Biol. 4, 339-342.

Noir, S., Combes, M.-C., Anthony, F. and Lashermes, P. (2001) Origin, diversity and evolution of NBS-type disease-resistance gene homologues in coffee trees (Coffea L.). Mol. Genet. Genomics, 265, 654-662.

Ogita, S., Uefuji, H., Yamaguchi, Y., Koizumi, N. and Sano, H. (2003) Producing decaffeinated coffee plants. Nature, 423, 823.

Park, J.M., Park, C.J., Lee, S.B., Ham, B.K., Shin, R. and Paek, K.H. (2001) Overexpression of the tobacco Tsil gene encoding an EREBP/AP2type transcription factor enhances resistance against pathogen attack and osmotic stress in tobacco. Plant Cell. 13, 1035-1046.

Ramalingam, J., Vera Cruz, C.M., Kukreja, K., Chittoor, J.M., Wu, J.L., Lee, S.W., Baraoidan, M., George, M.L., Cohen, M.B., Hulbert, S.H., Leach, J.E. and Leung, H. (2003) Candidate defense genes from rice, barley, and maize and their association with qualitative and quantitative resistance in rice. Mol. Plant-Microbe Interact. 16, 14-24.

Robatzek, S. and Somssich, I.E. (2001) A new member of the Arabidopsis WRKY transcription factor family, AtWRKY6, is associated with both senescence- and defence-related processes. Plant J. 28, 123-133.

Rodrigues, C.J., Jr, Bettencourt, A.J. and Rijo, L. (1975) Races of the pathogen and resistance to coffee rust. Annu. Rev. Phytopathol. 13, 49-70.

Rodrigues, C.J., Jr, Varzea, V., Godinho, I.L., Palma, S. and Rato, R.C. (1993) New physiological races of Hemileia vastatrix. Proceedings of the XV Scientific Colloquium on Coffee. Montpellier: ASIC.
Rozen, S. and Skaletsky, H.J. (2000) Primer3 on the WWW for general users and for biologist programmers. In Bioinformatics Methods and Protocols, Methods in Molecular Biology (Krawetz, S.M.S., ed.). Totowa, NJ: Humana Press, pp. 365-386.

Scheideler, M., Schlaich, N.L., Fellenberg, K., Beissbarth, T., Hauser, N.C., Vingron, M., Slusarenko, A.J. and Hoheisel, J.D. (2002) Monitoring the switch from housekeeping to pathogen defense metabolism in $A$. thaliana using CDNA arrays. J. Biol. Chem. 277, 10555-10561.

Schenk, P.M., Kazan, K., Wilson, I., Anderson, J.P., Richmond, T., Somerville, S.C. and Manners, J.M. (2000) Coordinated plant defense responses in Arabidopsis revealed by microarray analysis. Proc. Natl Acad. Sci. USA, 97, 11655-11660.

Shin, R., Park, J.M., An, J.M. and Paek, K.H. (2002) Ectopic expression of $T s i 1$ in transgenic hot pepper plants enhances host resistance to viral, bacterial, and oomycete pathogens. Mol. Plant-Microbe Interact. 15, 983-989.

Silva, M.C., Nicole, M., Guimaraes, L. and Rodrigues, C.J. Jr (2002) Hypersensitive cell death and post-haustorial defense responses arrest the orange rust (Hemileia vastatrix - race II) growth in resistant coffee leaves. Physiol. Mol. Plant Pathol. 60, 169-183.

Silva, M.C., Nicole, M., Rijo, L., Geiger, J.-P. and Rodrigues, C.J. Jr (1999) Cytochemical aspects of the plant-rust fungus interface during the compatible interaction Coffea arabica (cv. Caturra)-Hemileia vastatrix (race III). Int. J. Plant Sci. 160, 79-91.

Takemoto, D., Hayashi, M., Doke, N., Nishimura, M. and Kawakita, K. (1999) Molecular cloning of a defense-response-related cytochrome P450 gene from tobacco. Plant Cell Physiol. 40, 1232-1242.

Tao, Y., Xie, Z., Chen, W., Glazebrook, J., Chang, H.S., Han, B., Zhu, T., Zou, G. and Katagiri, F. (2003) Quantitative nature of Arabidopsis responses during compatible and incompatible interactions with the bacterial pathogen Pseudomonas syringae. Plant Cell, 15, 317-330.

Tkatchenko, A.V., Le Cam, G., Leger, J.J. and Dechesne, C.A. (2000) Large-scale analysis of differential gene expression in the hindlimb muscles and diaphragm of Mdx Mouse. Biochim. Biophys. Acta, 1500, 17-30.

Uefuji, H., Ogita, S., Yamaguchi, Y., Koizumi, N. and Sano, H. (2003) Molecular cloning and functional characterization of three distinct $\mathrm{N}$-methyltransferases involved in the caffeine biosynthetic pathway in coffee plants. Plant Physiol. 132, 372-380.

Vailleau, F., Daniel, X., Tronchet, M., Montillet, J.-L., Triantaphylidès, C. and Roby, D. (2002) A R2R3-MYB gene, AtMYB30, acts as a positive regulator of the hypersensitive cell death program in plants in response to pathogen attack. Proc. Natl Acad. Sci. USA, 99, 10179-10184.

White, O. and Kerlavage, A.R. (1996) TDB, new databases for biological discovery. Methods Enzymol. 266, 27-40.

Xiong, L., Lee, M.W., Qi, M. and Yang, Y. (2001) Identification of defenserelated rice genes by suppression subtractive hybridization and differential screening. Mol. Plant-Microbe Interact. 14, 685-692.

Zhou, N., Tootle, T.L. and Glazebrook, J. (1999) Arabidopsis PAD3, a gene required for camalexin biosynthesis, encodes a putative cytochrome P450 monooxygenase. Plant Cell, 11, 2419-2428. 